\title{
Response of fruit essences with Methyl eugenol to attract Bactrocera spp. at Chiku orchard
}

\author{
Shoaib Ali Shah ${ }^{1}$, Bhai Khan Solangi ${ }^{*}$, Imroz Solangi ${ }^{2}$, Asghar Ali \\ Majeedano ${ }^{3}$, Muhammad Ilyas Abro $^{3}$, Muhammad Akbar Lashari ${ }^{1}$, \\ Abdul Waris ${ }^{4}$, Sohail Iqbal ${ }^{4}$, Ghulam Hussain Alizai $^{4}$ and Mitha Khan ${ }^{4}$ \\ 1. Department of Entomology, Sindh Agriculture University, Tandojam-Pakistan \\ 2. Government College University Hyderabad-Pakistan \\ 3. College Education Department Govt. of Sindh-Pakistan \\ 4. Agriculture Research Institute Balochistan-Pakistan \\ *Corresponding author's email: $\underline{\text { bksolangi@gmail.com }}$ \\ Citation \\ Shoaib Ali Shah, Bhai Khan Solangi, Imroz Solangi, Asghar Ali Majeedano, Muhammad Ilyas Abro, Muhammad \\ Akbar Lashari, Abdul Waris, Sohail Iqbal, Ghulam Hussain Alizai and Mitha Khan. Response of fruit essences with \\ Methyl eugenol to attract Bactrocera spp. at Chiku orchard. Pure and Applied Biology. Vol. 10, Issue 3, pp922-927. \\ http://dx.doi.org/10.19045/bspab.2021.100095
}

Received: 01/10/2020 Revised: 18/12/2020

Accepted: 26/12/2020

Online First: 30/12/2020

\section{Abstract}

The experiment was conducted at the Chiku orchard, Sindh Agriculture University Tandojam during December 2016 to March 2017. Different essences were tested with Methyl eugenol i.e. pineapple (T1), banana (T2), cardamom (T3) and afza (T4) whereas methyl eugenol was used as control in (T5) without any essence with five replications through applying layout RCBD. Observations were recorded from December to March. Two fruit fly species; Bactrocera zonata and Bactrocera dorsalis were identified among the trapped species. Data represents that maximum mean number of B. zonatawas collectedT1 $(185.63 \pm 41.22)$ whereas; the minium mean number of $B$. zonata was T5 (126.44 \pm 21.49$)$. Overall mean number of $B$. zonata trapped was $185.63,164.25,126.94,179.68$ and 126.44 for T1, T2, T3, T4 and T5, respectively. Maximum captured pests were recorded in T1, whereas, minimum mean number of pests were captured in control trap. According to monthly observations the maximum numbers of B. zonata were trapped in the month of March (103.91 \pm 25.5$)$ whereas; where minimum number was recorded in the month of December (3.18 \pm 1.25$)$. The mean number of captured pests in January and February were $9.26 \pm 16.21$ and $40.33 \pm 2.83$ respectively. In the same way, maximum mean number of $B$. dorsalis was recorded in March (7.23 \pm 2.57$)$ and minimum numbers were observed in December $(0.19 \pm 0.17)$. Treatment wise the highest number of $B$. dorsalis was recorded at T1 (20.5) followed by T4 (17.84), T2 (11.05), T3 (9.5) and T5 (9.37). The relation of temperature with B. zonata and B. dorsalis observed as positive correlation: whereas it was observed as negative relation in order to humidity.

Keywords: Essences; Response; Methyl eugenol; Bactrocera; Chiku

\section{Introduction}

Chiku (Manilkara achras Mill.) is a green fruit plant, inhabitant of tropical America especially Southern Mexico in Dominant America and multiplied to other regions of world i.e. Philippines, Srilanka, Malaysia, India and Pakistan, where it was propagated very well [1]. While overall in world; India is considered as the largest producer of chiku where its states i.e. Tamil Nadu, Andhra 
Pardesh, Gujrat, Maharashtra and Karnatka contribute maximum part regarding its production. Although a climacteric fruit with very little shelf-life which cause almost 30$35 \%$ fruits perish as postharvest losses but categorized as a vital fruit in tropical regions [2].

It is a resistant cropbut can disturbed by several reasonsproduction and commercial worth of crop. Trees are attacked by different species of insects and mites throughout the year [3] described 25 species of insects and mites while recorded39 species of insect pests which have potential to cause damage to chiku crop. Among them serious pests Bactrocera zonata (Saunders) observed as major insect pest which cause heavy losses to chiku fruits in Asia. [4]. In Gujarat, several insect pests were reported which attack chiku all over the year and another species of (tephritidae) Bactrocera dorsalis (Hendel) also provide serious damage [5]. Female fly deposit itseggs in the targeted fruits, when they are physiologically suitable. After growth period, maggots start to feed on fruit pulp resultingfruits to become softer and staining which also promote secondary infestation by fungal and bacterial spp. [6]. The affected fruit drops prematurely and loose market value. Average financial loss of 29,460 million rupees per year due to attack of fruit fly on citrus, guava, chiku and mango is documented in India (Mumford, 2001). In gardening industry worldwide; fruit fly is considered as one of the most destructive insect pest globally. These flies damage about 40 fruit and vegetables species [7]. Fruit flies give direct commercial loss by fruit drop, damage and loss of market value. Infestation by fruit fly results severe threats financially to growers and dealers who are involved in this business. Furthermore due to its attack fruits could not become able to be exported. These insects are almost found anywhere in the world [8].
The B. dorsalis found in maximum climates, whereas Solanaceous found in both hot and cool climates. This also found in areas where annually average rainfall is about 100 inches. B. zonata is major pest of different areas of Asia continent where it can survive about 50 hosts i.e. peach, guava, mango, citrus, fig, apricot and chiku etc [9]. Almost 11 species are recorded in Pakistan which attack on different hosts plants, among these most serious are Bactrocera dorsalis, Bactrocera cucurbitae, Bactrocera zonata, Myiopardalis pardalina, Dacus diversus, Carpomiya incomplete, Dacus ferrugincus and Carpomiya vesuviana [10]. Fruit fly species infestation in Pakistan on different host plants i.e. Mango, guava, chiku, apple, ber, musk melon and bitter gourd [11]. The loss caused by fruit fly species in Pakistan is about 5\% to $100 \%$ [12]. About 200 million US dollar annually loss by fruit flies to growers, traders, retailers and exporters of vegetables and fruits is reported in Pakistan [13]. Fruit flies are widely attract adults to their death by the use of food baits which, mixed with pesticides. Over several years in South Asia a number of different lures have been assessed for the attraction of fruit flies, as well as protein hydrolysate [14]. Several yeast preparations, including $2 \%$ brewery waste in water, hydrolysed by oven sweltering at $40^{\circ} \mathrm{C}$ for 48 hours and $1 \%$ yeast protein and 1\% sugar .Management practices may need to be implemented if population are causing severe fruit damage. Therefore, this experiment was planned to observe the influence of various fruit essence with combination ofmethyl eugenol to attract fruit fly and its management atchiku orchard under field conditions.

\section{Materials and Methods}

The experiment was conducted during 20162017 at chiku orchard farm in Horticulture Garden at Sindh Agriculture University Tandojam, Sindh, Pakistan. 


\section{Pheromone bait \\ Treatment 1:}

(Methyl eugenol 85\% + sugar $10 \%+$ Insecticide Malathion $5 \%+2 \mathrm{ml}$ pine apple essence)

\section{Treatment 2:}

(Methyl eugenol 85\% + sugar $10 \%+$ Insecticide Malathion $5 \%+2 \mathrm{ml}$ banana essence)

\section{Treatment 3:}

(Methyl eugenol 85\% + sugar10\% + Insecticide Malathion 5\% $+2 \mathrm{ml}$ cardamom essence)

\section{Treatment 4:}

(Methyl eugenol 85\% + sugar 10\% + Insecticide Malathion $5 \%+2 \mathrm{ml}$ afza essence)

\section{Treatment 5:}

Control (Methyl eugenol 85\% + sugar10\% + Insecticide Malathion 5\%) only

\section{Pheromone traps}

Traps were used in this experiment by taking the size of $(36 \times 11 \times 16 \mathrm{~cm})$ which have tube shape upper concealment and with two openings at equal distance in each reverse direction. Cotton wicks used to absorb the treatment mixture and wrapped with the wire to attach with the trap. Experiment design rested out in randomized complete block design (RCBD) with five different treatments and individually treatment replicated four times. Each treatment contains two wicks of cotton one of methyl eugenol and other contain essence. Composition of trap solution methyl eugenol $(85 \%)$, sugar (10\%) and insecticide used 5\% for the killing of captured fruit flies, treatment five used without any essence as a control. The standard amount of methyl eugenol and essence were $2 \mathrm{ml} /$ trap. Temperature and relative humidity were noted regularly at field level. Trapped flies were counted accordingly on weekly basis.Cotton wicks were replaced on fortnightly basis. Data was analysed through
ANOVA by using Statix software and LSD test applied for mean separation.

\section{Results \\ Catching efficacy of different treatments against Bactrocera zonata}

Results in (Table 1) shows that the maximum population of $B$. zonata were attracted in the month of March (103.01 \pm 25.5 flies) while; minimum number of flies was captured in the month of December (3.18 \pm 1.25$)$. Individually number of collected flies in February and January remained 40.33 \pm 1.25 and $9.26 \pm 16.31$. Treatment wise result shows that highest captured flies were observed in T1 (125.5) and lowest in T5 (91.38) remaining flies observed as (111), (99.63) and (92.31) followed by $\mathrm{T} 2, \mathrm{~T} 4$ and $\mathrm{T} 3$ respectively. The statistical study shows that there was a significant difference $(\mathrm{p}<0.05)$ among whole treatments.

Monthly data shows that in December the maximum mean individuals were captured in T4 $(3.92 \pm 1.67)$ followed by $\mathrm{T} 2$ $3.75 \pm 1.47, \mathrm{~T} 31.75 \pm 0.78, \mathrm{~T} 12.5 \pm 1.46$ and T5 3.5 \pm 0.85 . In January, the highest number of $B$. zonata were observed from T4 $(10.75 \pm 37.38)$ and lowest number of individuals were captured in T5 (7.06 \pm 7.81$)$. Number of flies collected from T2, T1 and T3 were $10.25 \pm 15.05,9.75 \pm 10.34$ and $8.5 \pm 10.49$, respectively.

Data collecting results shows in the month of February discovered that greatest trap was T4 with mean number $(65.38 \pm 4.53)$ while; slightest number of flies were composed from T5 (24.38 \pm 2.85$)$. In remaining treatments, the mean number was $48.13 \pm 2.58,39.25 \pm 3.24$ and $24.5 \pm 1.41$ for T1, T2 and T3 respectively. According to last month March data collection results shows, the previous months trend replicated. The maximum number of $B$. zonata was collected from T1 (125.25 \pm 26.84$)$ followed by T2 $111 \pm 30, \quad \mathrm{~T} 4 \quad 99.63 \pm 31.99, \quad \mathrm{~T} 3$ $92.31 \pm 27.35$ and T5 91.38 \pm 11.42 . 
Trapping efficacy of different treatments against Bactrocera dorsalis

The results of (Table 2) shows that efficacy of various treatments is revealed. The data indicate that the maximum mean mass of $B$. dorsalis was collected in March (7.23 \pm 2.57$)$ and the lowestmass was collected in December $(0.19 \pm 0.17)$. According to treatment wise results indicate that the maximum flies attract in $\mathrm{T} 1$ (20.5) and minimum flies attract in T5 (9.37) remaining treatment results was in T4 (17.84), T2 (11.05) and T3 (9.5) respectively. According to monthly wise data the maximum and minimum both mean number of individuals captured was $(0.38 \pm 0.41),(0.00 \pm 0.00)$ in which treatment at $\mathrm{T} 4, \mathrm{~T} 1$. The mean collection of data on further traps were; T2 $(0.17 \pm 0.17), \quad \mathrm{T} 3 \quad(0.17 \pm 0.17) \quad$ and $\mathrm{T} 5$ $(0.25 \pm 0.08)$. In the next month January, the percentage of individuals increase in all treatments, as compare to last month. The uppermost quantity of flies were counted from T4 (2.69 \pm 4.85$)$ followed by $\mathrm{T} 1$ $(2.44 \pm 2.41), \mathrm{T} 2(2.00 \pm 1.28), \mathrm{T} 3(1.63 \pm 1.43)$ and T5 (1.5 \pm 1.77$)$. In the month of February

Table 1. Population of Bactrocera zonata recorded during different months due to the use of various food essences

\begin{tabular}{|c|c|c|c|c|c|}
\hline Treatment & December & January & February & March & Mean \\
\hline T1 & $2.5 \pm 1.46^{\mathrm{a}}$ & $9.75 \pm 10.34^{\mathrm{a}}$ & $48.13 \pm 2.58^{\mathrm{a}}$ & $125.25 \pm 26.84^{\mathrm{a}}$ & $185.63 \pm 41.22$ \\
\hline T2 & $3.75 \pm 1.47^{\mathrm{ab}}$ & $10.25 \pm 15.05^{\mathrm{ab}}$ & $39.25 \pm 3.24^{\mathrm{ab}}$ & $111 \pm 30^{\mathrm{ab}}$ & $164.25 \pm 49.76$ \\
\hline T3 & $1.75 \pm 0.78^{\mathrm{b}}$ & $8.5 \pm 10.49^{\mathrm{b}}$ & $24.5 \pm 1.41^{\mathrm{b}}$ & $92.31 \pm 27.35^{\mathrm{b}}$ & $126.94 \pm 41.47$ \\
\hline T4 & $3.92 \pm 1.67^{\mathrm{a}}$ & $10.75 \pm 37.38^{\mathrm{a}}$ & $65.38 \pm 4.53^{\mathrm{a}}$ & $99.33 \pm 31.99^{\mathrm{a}}$ & $179.68 \pm 75.57$ \\
\hline T5 & $3.5 \pm 0.85^{\mathrm{b}}$ & $7.06 \pm 7.81^{\mathrm{b}}$ & $24.38 \pm 2.85^{\mathrm{b}}$ & $92.31 \pm 27.35^{\mathrm{b}}$ & $126.44 \pm 21.49$ \\
\hline Total/average & $3.18 \pm 1.25$ & $9.26 \pm 16.31$ & $40.33 \pm 2.83$ & $103.91 \pm 25.5$ & \\
\hline
\end{tabular}

Table 2. Population of Bactrocera dorsalis recorded during different months due to the use of various food essences

\begin{tabular}{|c|c|c|c|c|c|}
\hline \multirow{2}{*}{ Treatment } & \multicolumn{5}{|c|}{ Month } \\
\cline { 2 - 6 } & December & January & February & March & Mean \\
\hline $\mathrm{T} 1$ & $0 \pm \mathrm{0}^{\mathrm{a}}$ & $2.44 \pm 2.41^{\mathrm{a}}$ & $8.25 \pm 0.92^{\mathrm{a}}$ & $9.81 \pm 2.96^{\mathrm{a}}$ & $20.5 \pm 6.29$ \\
\hline $\mathrm{T} 2$ & $0.17 \pm 0.17^{\mathrm{a}}$ & $2 \pm 1.28^{\mathrm{a}}$ & $1.44 \pm 1.05^{\mathrm{a}}$ & $7.44 \pm 2.09^{\mathrm{a}}$ & $11.05 \pm 4.59$ \\
\hline $\mathrm{T} 3$ & $0.17 \pm 0.17^{\mathrm{b}}$ & $1.63 \pm 1.43^{\mathrm{b}}$ & $2.13 \pm 0.60^{\mathrm{b}}$ & $5.44 \pm 2.14^{\mathrm{b}}$ & $9.5 \pm 4.99$ \\
\hline $\mathrm{T} 4$ & $0.38 \pm 0.41^{\mathrm{b}}$ & $2.69 \pm 4.85^{\mathrm{b}}$ & $6.44 \pm 1.85^{\mathrm{b}}$ & $7.88 \pm 3.23^{\mathrm{b}}$ & $17.84 \pm 10.34$ \\
\hline $\mathrm{T} 5$ & $0.25 \pm 0.08^{\mathrm{b}}$ & $1.5 \pm 1.77^{\mathrm{b}}$ & $2.19 \pm 0.72^{\mathrm{b}}$ & $5.56 \pm 2.42^{\mathrm{b}}$ & $9.37 \pm 4.34$ \\
\hline Total/average & $0.19 \pm 0.17$ & $2.05 \pm 2.35$ & $4.09 \pm 1.03$ & $7.23 \pm 2.57$ & \\
\hline
\end{tabular}


Table 3. Correlations of temperature and humidity with all treatments

\begin{tabular}{|c|c|c|}
\hline Correlation & B. zonata & B. dorsalis \\
\hline \multirow{2}{*}{ Temperature } & $\mathrm{r}=0.6023$ & 0.3955 \\
& $\mathrm{p}<0.001$ & $\mathrm{p}<0.001$ \\
\hline \multirow{2}{*}{ Relative Humidity } & -0.2887 & -0.2436 \\
& $\mathrm{p}<0.001$ & $\mathrm{p}<0.001$ \\
\hline
\end{tabular}

\section{Discussion}

This experiment was accomplished to detect the role of different essence with methyl eugenol catching or attracting more flies in chiku orchard. Different essences were used in this experiment such as: Pineapple, Banana, Cardamom and Afza essence traps suggestively showed significant attraction to $B$. zonata and $B$. dorsalis comparatively to without essence i.e. control (Methyl eugenol). In the same way, an experiment was carried out on different fruit essence i, e Pine apple, banana, raspberry and mango to capture more fruit flies $B$. zonata. It was healthier proved that to attracted B. Zonata; Mango and Pineapple essence were observed as significant trapping tool followed by other essence as well as traps without food essence i.e control [1] and inspection on consideration estimations shown that adding of food essence may boost the efficiency of methyl eugenol and cue lure traps having pesticides and sugar as lure element [1]. Furthermore it was reported that Pineapple essence traps, Banana essence traps and Mango essence traps significantly proved better and captured more $B$. dorsalis and B. zonatus as likened to other essences including traps without essence i.e. control [7]. This results of current study shows that Pineapple essence is more suitable with methyl eugenol to attract more flies similarly, [7] studied that Pine apple essence andRaspberry essence was most attractive essence traps of flies as compared to other essences and control.

This experiment results shows population of flies increase in March similarly describe population of $B$. dorsalis increased in
March. Study represents positive correlation with temperature and negative correlation in order to relative humidity. Similarly, Patel [5] indicated weather dynamics have significant effect on the population of fruit flies, among them rainfall was most important factor. Patel [5] described positive correlation of attracted individuals with temperature.

In this study different food essences were utilized to upgrade viability of pheromone traps to lure maximum population of fruit flies (B. zonata and B. dorsalis) and comparatively observed efficacy of different food essences as well as without any food essence. This one season study is not adequate to reach out significant determinations for the quality capability of the essences contemplate hence a broad level study is so far expected to additionally consider mentioned essences in various territories as well as in different fruits and vegetables. Besides the outcomes and commendation made in this study accomplished till now could be followed and applied accordingly. It is expected that these results will be helpful for farmer community and fruit flies could be controlled effectively by applying of natural substances without contaminating the earth and staying away from additional costs on inputs and risk to human health.

\section{Conclusion}

It is concluded that comparatively best essences to methyl eugenol in order to attract fruit flies are pineapple and afza.Maximum population of $B$. zonata and $B$. dorsalis was recorded during the month of March and February Moreover, temperature showed a positive and medium 
effect on the population of both species, whereas, relative humidity showed a negative but very weak relationship with both the species.

\section{Authors' contributions}

Conceived and designed the experiments: SA Shah \& BK Solangi, Performed the experiments: SA Shah, BK Solangi, I Solangi, AA Majeedano \& MI Baro, Analyzed the data: MA Lashari \& AWS Iqbal, Contributed materials/ analysis/ tools: SA Shah, BK Solangi, I Solangi, GH Alizai \& M Khan, Wrote the paper: SA Shah \& BK Solangi.

\section{References}

1. Chadha (1992). Studies on baits and dust formulations of insecticides against fruit fly (Diptera: Tephritidae), on melon under semi-arid conditions of Dera Ismail Khan. Pak J of Biol Sci 4: 334-335.

2. Khurana \& Kanawjia (2006). Nontraditional control of fruit flies, in guava orchards in Dera Ismail Khan. Pak J of Agric Res 17: 195-196.

3. Butani (1979). Comparison of different methods to control fruit fly (Carpomyia vesuviana), on ber Zizyphus mauritiana. Pak Entomol 27: 1-2.

4. Agarwal ML, Kumar P \& Kumar V (1999). Population suppression of Bactrocera dorsalis and Bactrocera zonata (Diptera: Tephritidae) in North Bihar, Shashpa 9(6): 189-191.

5. Patel (1981). Insects and fruits, Periodical Experiment Book Agency, New Delhi, 415.

6. White and Elson, 1994. Strategy for optimization of productivity and utilization of sapota. Indian $J$ of Hortic 49(1): 1-17.
7. Manzar \& Sirivastava (2004). Population dynamics of Bactrocera dorsalis (Diptera: Tephritidae) and analysis of the factors influencing the population in Ruili, Yunnan Province China. Acta Ecologica Sinica 26(9): 2801-2808.

8. Fletcher (1987). Comparison of the Efficacy of Different Food Attractant and Their Concentration for melon Fly (Diptera: Tephritidae). $J$ of Econ Entomol 96(1): 231-232.

9. Elson-Haris \& Ghanim (2009). Temperature development rate relationship of immature stage and adults of tephritid fruit fly. $J$ of Else Amst 273-289.

10. Abdullah et al., (2002). Studies on the peach fruit fly, Bactrocera zonata, (Tephritidae, Diptera). PhD. Thesis, Faculty of Agriculture, Mansoura University.

11. Ahmed et al. (1999). Effectiveness of fenitrothion bait spray against melon fruit flies, Dacus cucurbitae Coq. in bitter gourd. Indian J of Agric Res 16: 41-66.

12. Syed et al. (1970). Single -Killing-Point field assessment of bait and lure control of fruit flies (Diptera: Tephritidae) in Pakistan. J of Crop Prot 21(8): 651-659.

13. Stonehouse et al. (1998). Resistance in musk-melon (Cucumis melo L.) against melon fruit fly (Bactocera cucurbitae) and its chemical control, in Dera Ismail Khan. Pak J of Biol Sci 2: 1481-1483.

14. Gupta \& Verma (1982). Application of manothermosonication in food processing. Packaging India 39(3): 920. 